\title{
Modulation of myocardial contraction by peroxynitrite
}

\author{
Mark J. Kohr ${ }^{1,2}$, Steve R. Roof ${ }^{1}$, Jay L. Zweier ${ }^{3}$ and Mark T. Ziolo ${ }^{1 *}$ \\ 1 Department of Physiology and Cell Biology, Davis Heart and Lung Research Institute, The Ohio State University, Columbus, OH, USA \\ 2 Division of Cardiovascular Pathology, Department of Pathology, Johns Hopkins University, Baltimore, MD, USA \\ ${ }^{3}$ Department of Internal Medicine: Division of Cardiovascular Medicine, Davis Heart and Lung Research Institute, The Ohio State University, Columbus, OH, USA
}

\section{Edited by:}

Lars S. Maier,

Georg-August-Universität, Germany

Reviewed by:

Jens Kockskämper,

Philipps-University Marburg,

Germany

Christoph Maack,

Universitätsklinikum des

Saarlandes, Germany

${ }^{*}$ Correspondence:

Mark T. Ziolo, Department of

Physiology and Cell Biology, Davis

Heart and Lung Research Institute,

The Ohio State University, 304

Hamilton Hall, 1645 Neil Avenue,

Columbus, OH 43210, USA.

e-mail:ziolo.1@osu.edu
Peroxynitrite is a potent oxidant that is quickly emerging as a crucial modulator of myocardial function. This review will focus on the regulation of myocardial contraction by peroxynitrite during health and disease, with a specific emphasis on cardiomyocyte $\mathrm{Ca}^{2+}$ handling, proposed signaling pathways, and protein end-targets.

Keywords: myocyte, peroxynitrite, nitric oxide synthase, $\mathrm{Ca}^{2+}, \mathrm{cAMP}-$ dependent protein kinase, protein phosphatase 2a
The heart plays a vital role in the cardiovascular system by providing the specialized tissues and organs of the body with a continual supply of oxygen and other essential nutrients. Modulation of myocardial contraction allows the heart to meet the demands of the body despite continual changes in metabolism. This modulation occurs at several different levels, including the level of the ventricular cardiomyocyte.

\section{EXCITATION-CONTRACTION COUPLING}

Cardiomyocyte contraction occurs via a process termed excitation-contraction coupling, in which the electrical activity of the heart is translated into cardiomyocyte contraction (Bers, 2001, 2002). This process commences with the cardiac action potential and the depolarization of the myocyte membrane, which leads to the opening of L-type $\mathrm{Ca}^{2+}$ channels (Bers, 2001, 2002). This causes an influx of $\mathrm{Ca}^{2+}$ into the myocyte via the L-type $\mathrm{Ca}^{2+}$ current $\left(\mathrm{I}_{\mathrm{Ca}}\right)$, and subsequently triggers the opening of the sarcoplasmic reticulum (SR) $\mathrm{Ca}^{2+}$-release channels or ryanodine receptors (RyRs). This results in an efflux of $\mathrm{Ca}^{2+}$ from the SR, which is the major $\mathrm{Ca}^{2+}$ store in the cardiomyocyte, in a process termed $\mathrm{Ca}^{2+}$-induced $\mathrm{Ca}^{2+}$-release. This process initiates the upstroke of the myocyte $\left[\mathrm{Ca}^{2+}\right]_{\mathrm{i}}$ transient and this $\mathrm{Ca}^{2+}$ is now available for myocyte contraction. SR $\mathrm{Ca}^{2+}$ load, which represents the $\mathrm{Ca}^{2+}$ available for release from the SR, is a critical determinant of $\left[\mathrm{Ca}^{2+}\right]_{i}$ transient amplitude and thus myocyte contraction (Bassani et al., 1995; Trafford et al., 1995).

The $\left[\mathrm{Ca}^{2+}\right]_{\mathrm{i}}$ transient is responsible for the activation of cardiomyocyte contraction or shortening. When $\left[\mathrm{Ca}^{2+}\right]_{\mathrm{i}}$ increases within the cardiomyocyte, this $\mathrm{Ca}^{2+}$ diffuses to the myofilaments and binds to troponin C (TnC) (Davis and Tikunova, 2008). This induces a strong interaction between $\mathrm{TnC}$ and troponin I ( TnI), effectively destabilizing the interaction between $\mathrm{TnI}$ and actin. This shifts the troponin-tropomyosin complex in such a way as to allow the myosin head to bind directly to actin, thus leading to the formation of a myosin crossbridge. Provided that ATP is readily available to the myosin head, myocyte force production and/or shortening ensues until $\mathrm{Ca}^{2+}$ is no longer bound to TnC.

Relaxation is initiated by the decline of the $\left[\mathrm{Ca}^{2+}\right]_{i}$ transient, which is primarily mediated by the SR $\mathrm{Ca}^{2+}$. ATPase/phospholamban complex (SERCA/PLB) and the $\mathrm{Na}^{+} / \mathrm{Ca}^{2+}$ exchanger (NCX) (Bers, 2001, 2002). The SERCA/PLB complex serves to re-sequester $\mathrm{Ca}^{2+}$ into the SR, while NCX directly extrudes $\mathrm{Ca}^{2+}$ into the extracellular space. PLB is a phosphoprotein that plays a critical role in the decline of the $\left[\mathrm{Ca}^{2+}\right]_{\mathrm{i}}$ transient by regulating the uptake of $\mathrm{Ca}^{2+}$ by SERCA. Under basal conditions, PLB remains hypophosphorylated and serves to inhibit the uptake of $\mathrm{Ca}^{2+}$ by SERCA. This inhibition can be relieved upon PLB Serine16 phosphorylation by protein kinase A (PKA), thus allowing greater uptake of $\mathrm{Ca}^{2+}$ into the SR (Chu et al., 2000; Hagemann and Xiao, 2002; Mattiazzi et al., 2006). There are two main serine/threonine protein phosphatases that dephosphorylate PLB, protein phosphatase 1 (PP1) and protein phosphatase 2a (PP2a) (Macdougall et al., 1991).

\section{MODULATION OF EXCITATION-CONTRACTION COUPLING}

Since every cardiomyocyte is recruited to contract with each heartbeat, numerous endogenous systems have evolved to effectively regulate the ventricular myocyte contractile state by modulating excitation-contraction coupling. For example, stimulation of the $\beta$-adrenergic receptor ( $\beta$-AR) pathway results in positive inotropic and lusitropic effects via modulation of key excitationcontraction coupling proteins (Bers and Ziolo, 2001). Activation 
of the $\beta$-AR signaling pathway transpires with binding of an agonist (e.g., epinephrine, isoproterenol) to the receptor, which results in the dissociation of the $\mathrm{G}_{\mathrm{s} \alpha}$ subunit. $\mathrm{G}_{\mathrm{s} \alpha}$ induces cAMP production via adenylate cyclase $(A C)$. Increased cAMP then activates the cAMP-dependent protein kinase or PKA, which phosphorylates many different targets in the cardiomyocyte, including $\mathrm{I}_{\mathrm{Ca}}$, RyR, TnI, and PLB. The end result is increased $\mathrm{Ca}^{2+}$ influx, increased SR $\mathrm{Ca}^{2+}$ uptake, load, and release, and decreased myofilament $\mathrm{Ca}^{2+}$ sensitivity. PLB phosphorylation at Serine 16 by PKA is one of the primary mechanisms responsible for the observed positive inotropic and lusitropic effects of $\beta$-AR stimulation (Chu et al., 2000; Li et al., 2000; Roof et al., 2011, 2012). Therefore, altering PLB phosphorylation levels will lead to drastic changes in myocardial contraction and relaxation. Since the $\beta$-AR pathway is perhaps the most important regulator of myocardial contractility, this pathway itself is modulated by other endogenous systems such as reactive nitrogen species (RNS).

\section{REACTIVE NITROGEN SPECIES}

RNS are quickly emerging as crucial modulators of myocardial contraction during health and disease (Pacher et al., 2007). Alterations in the production of these reactive species may be responsible for part of the dysfunction that is observed during many pathophysiological conditions of the myocardium and may represent novel therapeutic targets. However, the modulation of myocardial function by RNS is a relatively new field and many questions remain unanswered. For example, studies have yet to conclusively determine whether this dysfunction results from the loss of endogenous RNS production [i.e., nitric oxide (NO)] or from the production of supraphysiological levels of reactive species. In all likelihood, this dysfunction stems from the partial loss of localized RNS signaling coupled with an increase in the production of more reactive species, including peroxynitrite. Indeed, this appears to be the case (Feldman et al., 2008; Ziolo et al., 2008).

$\mathrm{NO}$ is a well-known modulator of many physiological processes, including neural transmission and the regulation of blood pressure. However, NO is also surfacing as a key modulator of myocardial function by serving as a regulator of excitationcontraction coupling (Ziolo et al., 2001b, 2004; Wang et al., 2008a,b, 2009, 2010) and $\beta$-AR signaling (Balligand et al., 1993; Ziolo et al., 2001c). NO is produced endogenously within the myocardium by three distinct isoforms of NO synthase (NOS) (Ziolo and Bers, 2003). Neuronal NOS (NOS1) and endothelial NOS (NOS3) are constitutively expressed within cardiomyocytes. NOS1 and NOS3 produce low amounts of NO in phase with the myocyte $\left[\mathrm{Ca}^{2+}\right]_{\mathrm{i}}$ transient. Inducible NOS (NOS2), on the other hand, is only expressed within cardiomyocytes during inflammatory responses which occur during many pathophysiological conditions of the myocardium. NOS2 produces much higher amounts of $\mathrm{NO}$ compared to constitutive isoforms and is $\left[\mathrm{Ca}^{2+}\right]_{\mathrm{i}}$ independent (Schulz et al., 1992; Ziolo et al., 1998, 2001a).

$\mathrm{NO}$ is known to signal through at least two distinct signaling pathways: cGMP-dependent and cGMP-independent (Ziolo, 2008). cGMP-dependent signaling occurs through the activation of guanylate cyclase and protein kinase $\mathrm{G}(\mathrm{PKG})$, while cGMP-independent signaling primarily occurs via direct protein modification (e.g., S-nitrosylation) (Martinez-Ruiz and Lamas, 2004; Hess et al., 2005; Handy and Loscalzo, 2006; Kohr et al., $2011 b)$. NO has also been shown to directly activate AC independent of $\beta$-AR activation, thus resulting in positive inotropic effects via increased cAMP production and PKA activation (Vila-Petroff et al., 1999). NO also signals by coupling to other reactive signaling species (e.g., superoxide anion) to form related congeners, such as peroxynitrite.

\section{PEROXYNITRITE}

Peroxynitrite $\left(\mathrm{ONOO}^{-}\right)$is a potent oxidant that is formed upon the reaction of $\mathrm{NO}$ and superoxide. This reaction occurs with an extremely high rate constant, making the formation of peroxynitrite quite favorable (Huie and Padmaja, 1993; Beckman and Koppenol, 1996). Although peroxynitrite is a highly reactive species, it is still capable of diffusing through biological membranes and interacting with intracellular constituents (Denicola et al., 1998). Under physiological conditions, peroxynitrite production remains low and potential oxidative damage is reduced via endogenous cellular antioxidant defenses (Radi et al., 2002a,b). Low levels of peroxynitrite may also serve to modulate various intracellular signaling pathways. In fact, peroxynitrite appears to play a role in the regulation of many important physiological processes. For example, peroxynitrite has been demonstrated to modulate $\mathrm{T}$ cell proliferation (Brito et al., 1999; Vig et al., 2004), platelet aggregation (Schildknecht et al., 2008), and neutrophil adhesion (Zouki et al., 2001). Peroxynitrite is thought to mediate these physiological processes by targeting various proteins and/or signaling pathways, including receptor tyrosine kinases, mitogen-activated protein kinases, phosphoinositide 3-kinase/protein kinase B (Akt), protein kinase C, and nuclear factor $\mathrm{\kappa B}$ (Pacher et al., 2007).

The production of peroxynitrite increases greatly during the pathogenesis of numerous disorders, such as cerebral ischemiareperfusion (Thiyagarajan et al., 2004; Dhar et al., 2006), myocardial ischemia-reperfusion (Wang and Zweier, 1996; Cheung et al., 2000), heart failure (Ferdinandy et al., 2000; Mihm et al., 2001; Zhang et al., 2007), atherosclerosis (Buttery et al., 1996; Luoma et al., 1998), diabetes (Suarez-Pinzon et al., 1997, 2001), and septicemia (Bhattacharyya et al., 2004). Although peroxynitrite production plays a critical role for neutrophils and macrophages in microbial defense (Macmicking et al., 1997; Nathan and Shiloh, 2000), supraphysiological levels of peroxynitrite are almost always detrimental to cellular function. Peroxynitrite exerts damaging effects by altering protein structure and function via irreversible nitration to tyrosine residues and cysteine oxidation (Kamat, 2006; Pacher et al., 2007). Peroxynitrite can also exert effects by reacting with transition metal centers, including heme prosthetic groups (Pietraforte et al., 2001; Lin et al., 2007) and zinc-thiolate motifs (Crow et al., 1995; Zou et al., 2004), thus resulting in the inactivation of many enzymes. NOS3, an enzyme which exerts many cardioprotective effects (Janssens et al., 2004; Buys et al., 2007; Wang et al., 2008b, 2012), can be inhibited upon exposure to high levels of peroxynitrite (Zou et al., 2004; Chen et al., 2010). Additionally, hydroxylation of ring systems (Szabo et al., 1997; Tuo et al., 1998), DNA strand breakage (Szabo et al., 1996, 1997), and lipid peroxidation (Radi et al., 1991a,b) can be induced by 
peroxynitrite. Apoptosis and necrosis can also be triggered upon peroxynitrite exposure (Gilad et al., 1997; Arstall et al., 1999; Pacher et al., 2002; Levrand et al., 2006). Moreover, peroxynitrite will react with other molecules, such as carbon dioxide $\left(\mathrm{CO}_{2}\right)$, to form additional reactive species (i.e., nitrosoperoxycarbonate) (Uppu and Pryor, 1996). Increased peroxynitrite production is further compounded by the depletion of endogenous antioxidant pools, including glutathione (GSH), which is a major scavenger of reactive oxygen and nitrogen species (Valko et al., 2007). The production of peroxynitrite occurs endogenously in several different ways.

Peroxynitrite can be formed endogenously within the ventricular cardiomyocyte through various routes under physiological and pathophysiological conditions. A major source for the production of peroxynitrite includes the NOS isoforms (namely NOS1 and NOS2) and via non-classical pathways (namely nitroxyl).

NOS1 has been shown to co-immunoprecipitate with xanthine oxidoreductase (Khan et al., 2004), a superoxide producing enzyme. This interaction between NOS1 and xanthine oxidoreductase will lead to the physiological production of low levels of peroxynitrite. Additionally, NOS1 can potentially produce both NO and superoxide (Pou et al., 1992; Xia et al., 1996), although this is more likely to occur with NOS uncoupling during various disease states (Sun et al., 2008). NOS uncoupling will increase superoxide production by NOS1, while decreasing NO production. NOS1 is considered to be a physiological regulator of myocardial function by increasing basal contractility, the force-frequency response, and the response to $\beta$-AR stimulation (Barouch et al., 2002; Khan et al., 2003; Vandsburger et al., 2007; Wang et al., 2008a, 2010).

NOS2 is a high output NOS isoform and can readily become uncoupled upon depletion of the cofactors necessary for NO production, thus leading to the production of both NO and superoxide (Xia and Zweier, 1997; Mungrue et al., 2002). Additionally, NADPH oxidase and xanthine oxidoreductase can increase superoxide production under the same pathophysiological conditions in which NOS2 is expressed (Heymes et al., 2003; Minhas et al., 2006). This will lead to the production of supraphysiological levels of peroxynitrite. NOS2 is considered to be a pathophysiological regulator of myocardial function by decreasing the response to $\beta$-AR stimulation (Drexler et al., 1998; Ziolo et al., 2001b, 2004).

In addition to the NO produced via NOS1 and NOS2, additional sources of peroxynitrite include nitroxyl, the one electron reduction production of NO (Kirsch and De Groot, 2002). Endogenous production of nitroxyl within cardiomyocytes may occur through various routes, including via hydrogen atom extraction by NO (Akhtar et al., 1985). NOS1 also remains a potential source for the production of nitroxyl (Schmidt et al., 1996; Ishimura et al., 2005). Therefore, the reaction of nitroxyl with $\mathrm{O}_{2}$ will lead to the production of low levels of peroxynitrite.

\section{PEROXYNITRITE AND CARDIOMYOCYTE CONTRACTION}

Recent work has now demonstrated that peroxynitrite is able to modulate excitation-contraction coupling, and hence contractility. In the myocardium, peroxynitrite has been demonstrated to exert biphasic effects on cardiomyocyte contraction.
More specifically, low levels of peroxynitrite (which occurs under physiological conditions) have been shown to produce positive inotropic effects on cardiomyocyte function. Conversely, high levels of peroxynitrite (which occurs under pathophysiological conditions) are extremely detrimental to myocardial function by decreasing cardiomyocyte contraction.

\section{PHYSIOLOGICAL REGULATION OF CARDIOMYOCYTE CONTRACTION BY PEROXYNITRITE}

Many studies have shown that low levels of peroxynitrite induce positive inotropic effects on basal myocardial function. Chesnais et al. demonstrated peroxynitrite to increase force production in frog atrial and ventricular fibers using authentic peroxynitrite, as well as the peroxynitrite donor SIN-1 (Chesnais et al., 1999a,b). Paolocci et al. confirmed this positive effect on basal function in mammalian ex vivo myocardial preparations using SIN-1 (Paolocci et al., 2000). Interestingly, this effect was reversed with GSH and occurred independently from global changes in cAMP and cGMP levels. Furthermore, we demonstrated that a low concentration of peroxynitrite increased basal and submaximal $\beta$-AR-stimulated contraction in isolated cardiomyocytes (Kohr et al., 2008a). We next investigated the molecular mechanisms of this peroxynitrite-induced increase in basal contraction and found that it was dependent upon PLB. That is, peroxynitrite had no effect on basal contraction in PLB knockout myocytes. Further explorations demonstrated that peroxynitrite resulted in the enhancement of PLB Serine16 (the PKA site) phosphorylation (Kohr et al., 2010) and was abolished upon inhibition of PKA with KT5720 (Kohr et al., 2010). Low peroxynitrite also increased PKA activity in cardiac homogenates and in purified preparations of PKA containing both the regulatory and catalytic subunits of PKA, indicating that peroxynitrite induces a direct, cAMP-independent activation of PKA. This direct effect may occur via $S$-nitrosylation, $S$-glutathiolation and/or cysteine oxidation (Ferdinandy, 2006; Pacher et al., 2007), as PKA has several cysteine residues which are susceptible to these types of modifications (Brennan et al., 2006; Burgoyne and Eaton, 2009; Kohr et al., 2011a). Thus, low levels of peroxynitrite shift the kinase/phosphatase balance leading to increased PLB phosphorylation. Interestingly, the effect of low peroxynitrite on submaximal $\beta$-AR-stimulated contraction was still observed in PLB knockout myocytes, suggesting another protein target. A recent study demonstrated that PKA phosphorylation of RyR contributes to the inotropic effect of $\beta$-AR stimulation using a low dose of isoproterenol (Shan et al., 2010). Thus, peroxynitrite-mediated activation of PKA may also lead to RyR phosphorylation contributing to the contractile effects of $\beta$-AR stimulation. Non PKA-mediated effects of peroxynitrite have also been reported such as $S$-nitrosylation of SERCA2a, which increases $\mathrm{Ca}^{2+}$ uptake and relaxation (Bencsik et al., 2008).

We previously demonstrated in healthy ventricular cardiomyocytes that NOS1 signals partly through the production of peroxynitrite (Wang et al., 2008a). Additionally, we and others have shown that NOS1 signaling increases myocardial contraction (basal, force-frequency response and $\beta$-AR-stimulated contraction) (Barouch et al., 2002; Khan et al., 2004; Wang et al., 2008a), parameters that can be considered physiologic. These effects are 
consistent with the positive inotropic effects of peroxynitrite (i.e., peroxynitrite increased basal and submaximal $\beta$-AR-stimulated contraction). Interestingly, $\mathrm{NOS}^{-/-}$myocytes exhibit reduced basal contraction and a diminished response to $\beta$-AR stimulation compared to wild type (Barouch et al., 2002; Khan et al., 2004; Wang et al., 2008a), which we and others demonstrated to occur in part through a reduction in RyR activity (Wang et al., 2010) and PLB Serine16 phosphorylation (Wang et al., 2008a; Zhang et al., 2008). This is also consistent with the PLB and RyR dependent effects of low peroxynitrite (Kohr et al., 2008a). In addition, NOS1 has been shown to potentially modulate PKA activity, as PKA inhibition decreased PLB Serine16 phosphorylation and the rate of relaxation in wild-type myocytes, but had no effect in NOS1 ${ }^{-/-}$myocytes (Zhang et al., 2008). Therefore, the physiological production of low levels of peroxynitrite may serve to maintain and/or increase basal and $\beta$-AR-stimulated myocyte contraction, in part, through a direct, cAMP-independent activation of PKA. Further, the loss of localized NOS1-mediated peroxynitrite production under certain disease states where NOS1 translocates to the sarcolemma (Damy et al., 2003, 2004) may result in decreased myocyte contraction similar to that observed with the knockout of NOS1.

\section{PATHOPHYSIOLOGICAL REGULATION OF CARDIOMYOCYTE CONTRACTION BY PEROXYNITRITE}

At high concentrations, peroxynitrite is detrimental to myocardial function. Studies examining high levels of peroxynitrite have demonstrated dysfunctional effects via direct exposure or using peroxynitrite donors (Lopez et al., 1997; Ma et al., 1997; Ferdinandy et al., 1999, 2000; Katori et al., 2006). Additionally, we have demonstrated a NOS2-induced reduction in $\beta$-ARstimulated RyR activity through a cGMP-independent mechanism, likely via peroxynitrite (Ziolo et al., 2001b). Further, we and others have shown a reduction in $\beta$-AR-stimulated contraction upon exposure to a high concentration of SIN-1 in isolated cardiomyocytes (Stojanovic et al., 2001; Yin et al., 2002). We demonstrated that this SIN-1-induced decrease in $\beta$-AR-stimulated contraction occurred via peroxynitrite formation and was also dependent upon PLB. However, unlike low peroxynitrite, high peroxynitrite results in a reduction in PKAdependent PLB Serine16 phosphorylation (Kohr et al., 2008b). Upon further examination of this signaling pathway, we determined that high peroxynitrite increased phosphatase activity in cardiac homogenates (low peroxynitrite had no effect on phosphatase activity). Interestingly, it appears that peroxynitrite selectively targets PP2a as we observed an increased interaction between PLB and PP2a (but not PP1) with peroxynitrite (Kohr et al., 2009). This reversible effect may occur through a protein intermediate or from the direct modification of PP2a by peroxynitrite via $S$-nitrosylation, $S$-glutathiolation, and/or cysteine oxidation (Ferdinandy, 2006; Pacher et al., 2007). PP2a has several cysteine residues which are susceptible to these types of modifications (Sommer et al., 2002). Consistent with our results, peroxynitrite has been shown to directly activate PP2a via tyrosine nitration in endothelial cells (Wu and Wilson, 2009). Thus, high levels of peroxynitrite shift the kinase/phosphatase balance leading to decreased PLB phosphorylation. While PP2A also modulates RyR phosphorylation (Terentyev et al., 2003), we did not observe any effects of high peroxynitrite on the $\beta$-AR response in PLB knockout myocytes, which suggests that this may be a compartmentalized effect targeted to PLB.

The production of high levels of peroxynitrite in the myocardium is often associated with the expression of NOS2 (Xia et al., 1998; Mungrue et al., 2002) and increased ROS production via NADPH oxidase (Byrne et al., 2003; Heymes et al., 2003) and xanthine oxidase (Tziomalos and Hare, 2009). Specifically in heart failure, studies have shown an increase in peroxynitrite production (Ferdinandy et al., 2000; Mihm et al., 2001; Zhang et al., 2007), as well as a diminished response to $\beta$-AR stimulation (Houser et al., 2000). We have previously demonstrated that myocytes isolated from failing human hearts expressing NOS2, displayed a blunted response to $\beta$-AR stimulation (Ziolo et al., 2004). This dysfunction could be reversed upon acute inhibition of NOS2, such that peak $\left[\mathrm{Ca}^{2+}\right]_{i}$ and cell shortening were significantly increased. This same functional phenomenon was observed with high peroxynitrite (i.e., peroxynitrite decreased contraction during $\beta$-AR stimulation). Interestingly, PP2a activity has been shown to be increased in heart failure (Boknik et al., 2000), while PLB Serine16 phosphorylation has been shown to be decreased (Bartel et al., 1996; Schwinger et al., 1999; Sande et al., 2002). Therefore, the increased formation of peroxynitrite that occurs in heart failure may be an important component of the $\beta$-AR dysfunction observed in heart failure and other cardiomyopathies. A recent study demonstrated that peroxynitrite was an independent risk predictor of post-operative complications (i.e., atrial fibrillation, need for inotropic support, length of hospital stay) among patients undergoing cardiac surgery for various reasons (Antoniades et al., 2012), further validating the significance of increased peroxynitrite in cardiac dysfunction.

\section{PEROXYNITRITE AND MITOCHONDRIAL FUNCTION}

The processes of cardiomyocyte contraction and $\mathrm{Ca}^{2+}$ reuptake/extrusion are dependent upon ATP. Through oxidative phosphorylation, mitochondria produce the majority of the ATP that is necessary for these processes. $\mathrm{Ca}^{2+}$ is also taken up by the mitochondria during each $\mathrm{Ca}^{2+}$ transient, and this serves to couple excitation-contraction coupling with energetic demand (Maack and O'Rourke, 2007). Recent work has demonstrated that mitochondrial function is modulated by RNS (i.e., NO, peroxynitrite).

NO is a well-established physiological mediator of mitochondrial respiration, and these effects primarily result from the inhibition of Complex I and IV of the electron transport chain (Brookes, 2004). Although Complex I and IV are similarly inhibited by NO, this inhibition occurs through two distinct mechanisms. In the case of Complex I, NO acts via $S$-nitrosylation of the $75 \mathrm{kDa}$ subunit of Complex I (Burwell et al., 2006). Complex $\mathrm{IV}$, on the other hand, is inhibited through the reaction of NO with the catalytic metals located in the active site of cytochrome c oxidase (Cleeter et al., 1994; Palacios-Callender et al., 2004). $\mathrm{NO}$ can also target additional mitochondrial proteins by reacting with superoxide to yield peroxynitrite. The effects of peroxynitrite on mitochondrial function are much less defined when compared to those of NO, but peroxynitrite has the potential to signal physiologically in the mitochondria or to contribute to mitochondrial dysfunction during pathological states. 
Peroxynitrite has been shown to target many different proteins in the mitochondria and this can occur via $S$-nitrosylation, as reported to occur with Complex I of the electron transport chain (Borutaite et al., 2000), or through irreversible nitration and/or cysteine oxidation. The reversibility of $S$-nitrosylation may represent a potential physiological signaling pathway for peroxynitrite in the mitochondria, while the effects of irreversible nitration and cysteine oxidation are likely to be highly detrimental to mitochondrial function. For example, peroxynitrite induced the irreversible inhibition of mitochondrial creatine kinase, and this effect could not be reversed with GSH treatment (Konorev et al., 1998). Peroxynitrite was also shown to inactivate the Kreb's cycle enzyme aconitase (Castro et al., 1994). Additional mitochondrial targets of peroxynitrite include the adenine nucleotide translocase (Vieira et al., 2001), nicotinamide nucleotide transhydrogenase (Forsmark-Andree et al., 1996), and Complex I, II, and V of the electron transport chain (Radi et al., 1994; Cassina and Radi, 1996; Riobo et al., 2001). Manganese superoxide dismutase, which is a major enzyme for the decomposition of superoxide in the mitochondria, is another target of peroxynitrite and is inactivated via nitration (Quijano et al., 2001). This peroxynitrite-induced inactivation is further compounded by increased levels of superoxide, which could in turn lead to the formation of additional peroxynitrite. Hence, a decrease in energy supply by inhibiting mitochondrial function could contribute to the depressed contractile function associated with high levels of peroxynitrite.

\section{LOW vs. HIGH LEVELS OF PEROXYNITRITE}

Peroxynitrite has a biphasic effect on cardiomyocyte contraction, which is mainly concentration dependent (low vs. high).
However, since peroxynitrite is highly reactive and rapidly decomposed, accurate measurements of concentration are difficult. In addition, determining intracellular concentrations of peroxynitrite with exogenously applied authentic peroxynitrite or the peroxynitrite donor SIN-1 is challenging, making direct comparisons to endogenously produced peroxynitrite formidable. In general, concentrations of $30 \mu \mathrm{M}$ or less of authentic peroxynitrite or $100 \mu \mathrm{M}$ or less of SIN-1 will result in positive inotropic effects as described. We have previously reported that $10 \mu \mathrm{M}$ SIN-1 produces $3 \mathrm{nM} / \mathrm{min}$ peroxynitrite in our physiological saline solution (Kohr et al., 2008a). Higher concentrations $(100 \mu \mathrm{M}$ authentic peroxynitrite or $200 \mu \mathrm{M}$ SIN-1) will result in negative inotropic effects as described. We have previously reported that $200 \mu \mathrm{M}$ SIN-1 results in a $6 \mathrm{X}$ greater production of peroxynitrite compared to $10 \mu \mathrm{M}$ SIN-1 (Kohr et al., 2008b). We consider these levels to be physiologically and pathophysiologically relevant as we and others observed similar effects on function in studies investigating NOS1 and NOS2 signaling. Thus, these concentrations of peroxynitrite result in the activation of various signaling pathways (PKA, PP2A, $S$-nitrosylation, etc.) resulting in the enhancement or reduction of myocardial contractility. There have been exceptions reported in which low concentrations of authentic peroxynitrite/SIN1 resulted in negative inotropic effects or high concentrations of SIN-1 resulted in positive inotropic effects (Yin et al., 2002; Katori et al., 2006; Kohr et al., 2008a). Thus, other factors also contribute to the contractile effects of peroxynitrite such as cardiomyocyte contractile state, signaling pathway activation (e.g., $S$-nitrosylation, nitration, cGMP or cAMP) as well as the length of exposure (Schulz et al., 1997; Ziolo, 2008).

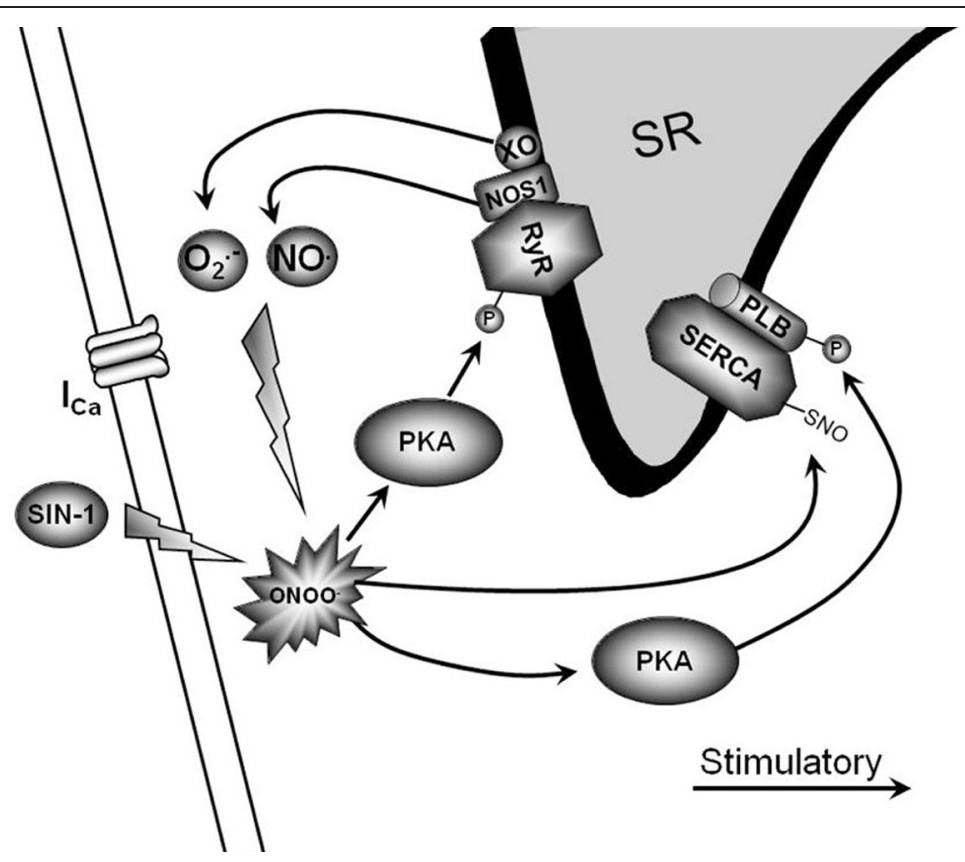

FIGURE 1 | Physiological signaling pathway of low peroxynitrite. This is a diagrammatic representation of low peroxynitrite signaling and various proposed end targets within the cardiomyocyte. The endogenous production of low peroxynitrite can occur via NOS1/xanthine oxidase. 


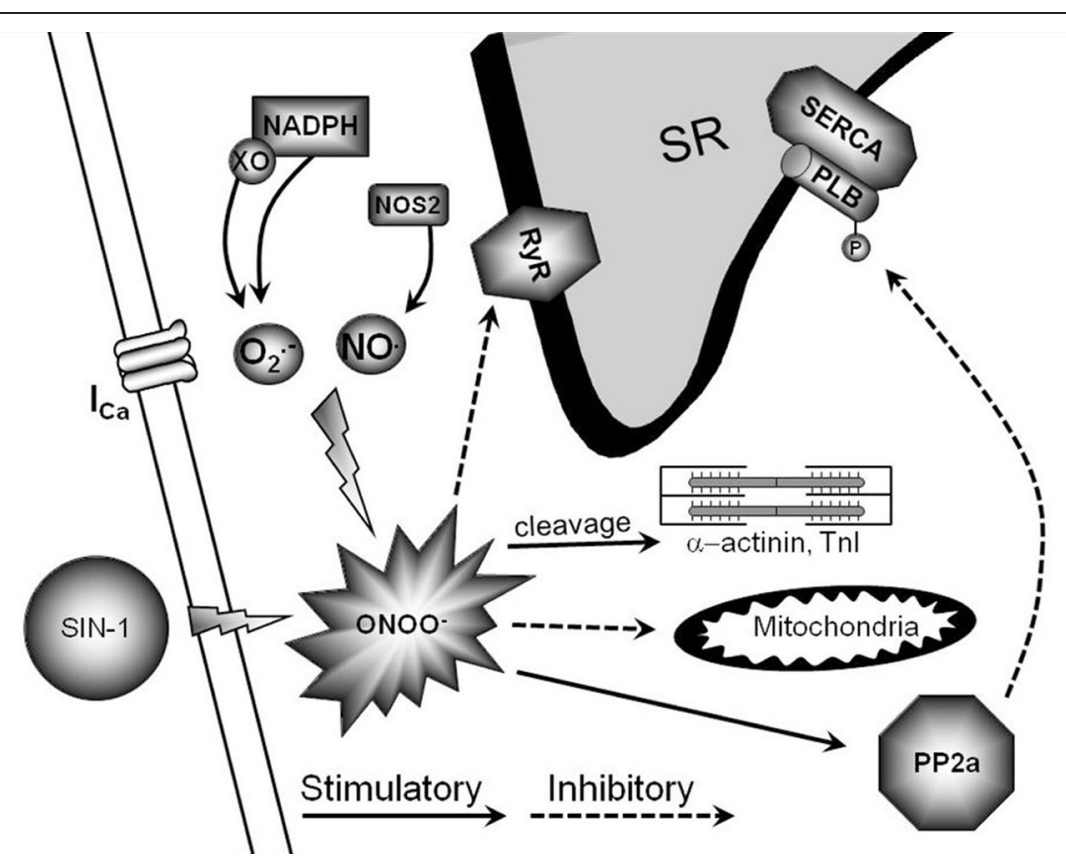

FIGURE 2 | Pathophysiological signaling pathway of high peroxynitrite. This is a diagrammatic representation of high peroxynitrite signaling and various proposed end targets within the cardiomyocyte. The endogenous production of high levels of peroxynitrite can occur via NOS2/NADPH oxidase/xanthine oxidase.

Studies have also been performed using very high concentrations of authentic peroxynitrite $(\mathrm{mM})$ or long exposure times. These studies revealed irreversible effects of peroxynitrite that depressed myocyte contraction and inactivated SERCA (Ishida et al., 1996; Knyushko et al., 2005; Lokuta et al., 2005). A consequence of this very high concentration of peroxynitrite is likely a toxic effect that results in cell damage. For example, peroxynitrite is able to activate matrix metalloproteinases that will result in the cleavage of $\alpha$-actinin and TnI (Wang et al., 2002; Rork et al., 2006; Sung et al., 2007; Leon et al., 2008). We believe that very high concentrations of peroxynitrite can be produced in certain disease states such as heart failure or ischemia/reperfusion injury which have reported SERCA inactivation via nitration or TnI cleavage.

In conclusion, peroxynitrite is emerging as a crucial modulator of myocardial function during health and disease. Under physiological conditions, low levels of peroxynitrite serve to maintain and/or increase basal and $\beta$-AR-stimulated contraction in

\section{REFERENCES}

Akhtar, M. J., Bonner, F. T., and Hughes, M. N. (1985). Reaction of nitric oxide with hyponitrous acid: a hyrdogen atom abstraction reaction. Inorg. Chem. 24, 1934-1935.

Antoniades, C., Demosthenous, M., Reilly, S., Margaritis, M., Zhang, M. H., Antonopoulos, A., et al. (2012). Myocardial redox state predicts in-hospital clinical outcome after cardiac surgery effects of shortterm pre-operative statin treatment. J. Am. Coll. Cardiol. 59, 60-70.
Arstall, M. A., Sawyer, D. B., Fukazawa, R., and Kelly, R. A. (1999). Cytokine-mediated apoptosis in cardiac myocytes: the role of inducible nitric oxide synthase induction and peroxynitrite generation. Circ. Res. 85, 829-840.

Balligand, J. L., Kelly, R. A., Marsden, P. A., Smith, T. W., and Michel, T. (1993). Control of cardiac musnous nitric oxide signaling system. Proc. Natl. Acad. Sci. U.S.A. 90, $347-351$. cle cell function by an endoge-

the myocardium. This occurs via RyR and PLB phosphorylation through direct PKA activation and SERCA activation via S-nitrosylation (Figure 1). Conversely, supraphysiological levels of peroxynitrite (due to NOS2 expression and increased ROS levels via NADPH oxidase and xanthine oxidase) are detrimental to myocardial function and decrease $\beta$-AR-stimulated cardiomyocyte contraction. This occurs via PLB dephosphorylation through PP2a activation, decreased RyR activity, mitochondrial dysfunction, and myofilament protein cleavage (Figure 2). This dual effect lends critical insight into the physiological and pathophysiological regulation of myocardial contraction by peroxynitrite.

\section{ACKNOWLEDGMENTS}

Supported by the American Heart Association (Pre-doctoral Fellowship 0715159B, Mark J. Kohr) and the National Institutes of Health (K02HL094692, R01HL079283, Mark T. Ziolo; R01HL38324, HL63744, HL65608, Jay L. Zweier).

Barouch, L. A., Harrison, R. W., Skaf, M. W., Rosas, G. O., Cappola, T. P., Kobeissi, Z. A., et al. (2002). Nitric oxide regulates the heart by spatial confinement of nitric oxide synthase isoforms. Nature 416, 337-339.

Bartel, S., Stein, B., Eschenhagen, T., Mende, U., Neumann, J., Schmitz, W., et al. (1996). Protein phosphorylation in isolated trabeculae from nonfailing and failing human hearts. Mol. Cell. Biochem. 157, 171-179.
Bassani, J. W., Yuan, W., and Bers, D. M. (1995). Fractional SR Ca release is regulated by trigger $\mathrm{Ca}$ and $\mathrm{SR}$ Ca content in cardiac myocytes. Am. J. Physiol. 268, C1313-C1319.

Beckman, J. S., and Koppenol, W. H. (1996). Nitric oxide, superoxide, and peroxynitrite: the good, the bad, and ugly. Am. J. Physiol. 271, C1424-C1437.

Bencsik, P., Kupai, K., Giricz, Z., Gorbe, A., Huliak, I., Furst, S., et al. (2008). Cardiac capsaicin-sensitive sensory nerves regulate myocardial 
relaxation via S-nitrosylation of SERCA: role of peroxynitrite. $\mathrm{Br}$. J. Pharmacol. 153, 488-496.

Bers, D. M. (2001). ExcitationContraction Coupling and Cardiac Contractile Force. Dordrecht, Netherlands: Kluwer Academic Publishers.

Bers, D. M. (2002). Cardiac excitationcontraction coupling. Nature 415, 198-205.

Bers, D. M., and Ziolo, M. T. (2001). When is cAMP not cAMP? Effects of compartmentalization. Circ. Res. 89, 373-375.

Bhattacharyya, J., Biswas, S., and Datta, A. G. (2004). Mode of action of endotoxin: role of free radicals and antioxidants. Curr. Med. Chem. 11, 359-368.

Boknik, P., Fockenbrock, M., Herzig, S., Knapp, J., Linck, B., Luss, H., et al. (2000). Protein phosphatase activity is increased in a rat model of long-term beta-adrenergic stimulation. Naunyn Schmiedebergs Arch. Pharmacol. 362, 222-231.

Borutaite, V., Budriunaite, A., and Brown, G. C. (2000). Reversal of nitric oxide-, peroxynitrite- and Snitrosothiol-induced inhibition of mitochondrial respiration or complex I activity by light and thiols. Biochim. Biophys. Acta 1459, 405-412.

Brennan, J. P., Bardswell, S. C., Burgoyne, J. R., Fuller, W., Schroder, E., Wait, R., et al. (2006). Oxidantinduced activation of type I protein kinase A is mediated by RI subunit interprotein disulfide bond formation. J. Biol. Chem. 281, 21827-21836.

Brito, C., Naviliat, M., Tiscornia, A. C., Vuillier, F., Gualco, G., Dighiero, G., et al. (1999). Peroxynitrite inhibits $\mathrm{T}$ lymphocyte activation and proliferation by promoting impairment of tyrosine phosphorylation and peroxynitrite-driven apoptotic death. J. Immunol. 162, 3356-3366.

Brookes, P. S. (2004). Mitochondrial nitric oxide synthase. Mitochondrion 3, 187-204.

Burgoyne, J. R., and Eaton, P. (2009). Transnitrosylating nitric oxide species directly activate type I protein kinase A, providing a novel adenylate cyclase-independent cross-talk to beta-adrenergic-like signaling. J. Biol. Chem. 284, 29260-29268.

Burwell, L. S., Nadtochiy, S. M., Tompkins, A. J., Young, S., and Brookes, P. S. (2006). Direct evidence for S-nitrosation of mitochondrial complex I. Biochem. J. 394, 627-634.
Buttery, L. D., Springall, D. R., Chester, A. H., Evans, T. J., Standfield, E. N., Parums, D. V., et al. (1996). Inducible nitric oxide synthase is present within human atherosclerotic lesions and promotes the formation and activity of peroxynitrite. Lab. Invest. 75, 77-85.

Buys, E. S., Raher, M. J., Blake, S. L., Neilan, T. G., Graveline, A. R., Passeri, J. J., et al. (2007). Cardiomyocyte-restricted restoration of nitric oxide synthase 3 attenuates left ventricular remodeling after chronic pressure overload. Am. J. Physiol. Heart Circ. Physiol. 293, H620-H627.

Byrne, J. A., Grieve, D. J., Cave, A. C., and Shah, A. M. (2003). Oxidative stress and heart failure. Arch. Mal. Coeur Vaiss. 96, 214-221.

Cassina, A., and Radi, R. (1996). Differential inhibitory action of nitric oxide and peroxynitrite on mitochondrial electron transport. Arch. Biochem. Biophys. 328, 309-316.

Castro, L., Rodriguez, M., and Radi, R. (1994). Aconitase is readily inactivated by peroxynitrite, but not by its precursor, nitric oxide. J. Biol. Chem. 269, 29409-29415.

Chen, W., Druhan, L. J., Chen, C. A., Hemann, C., Chen, Y. R., Berka, V., et al. (2010). Peroxynitrite induces destruction of the tetrahydrobiopterin and heme in endothelial nitric oxide synthase: transition from reversible to irreversible enzyme inhibition. Biochemistry 49, 3129-3137.

Chesnais, J. M., Fischmeister, R., and Mery, P. F. (1999a). Peroxynitrite is a positive inotropic agent in atrial and ventricular fibres of the frog heart. J. Physiol. 521, 375-388.

Chesnais, J. M., Fischmeister, R., and Mery, P. F. (1999b). Positive and negative inotropic effects of $\mathrm{NO}$ donors in atrial and ventricular fibres of the frog heart. J. Physiol. 518, 449-461.

Cheung, P. Y., Wang, W., and Schulz, R. (2000). Glutathione protects against myocardial ischemia-reperfusion injury by detoxifying peroxynitrite. J. Mol. Cell. Cardiol. 32, 1669-1678.

Chu, G., Lester, J. W., Young, K. B., Luo, W., Zhai, J., and Kranias, E. G. (2000). A single site (Ser16) phosphorylation in phospholamban is sufficient in mediating its maximal cardiac responses to beta -agonists. J. Biol. Chem. 275, 38938-38943.

Cleeter, M. W., Cooper, J. M., DarleyUsmar, V. M., Moncada, S., and Schapira, A. H. (1994). Reversible inhibition of cytochrome $c$ oxidase, the terminal enzyme of the mitochondrial respiratory chain, by nitric oxide. Implications for neurodegenerative diseases. FEBS Lett. 345, 50-54.

Crow, J. P., Beckman, J. S., and McCord, J. M. (1995). Sensitivity of the essential zinc-thiolate moiety of yeast alcohol dehydrogenase to hypochlorite and peroxynitrite. Biochemistry 34, 3544-3552.

Damy, T., Ratajczak, P., Robidel, E., Bendall, J. K., Oliviero, P., Boczkowski, J., et al. (2003). Upregulation of cardiac nitric oxide synthase 1-derived nitric oxide after myocardial infarction in senescent rats. FASEB J. 17, 1934-1936.

Damy, T., Ratajczak, P., Shah, A. M. Camors, E., Marty, I., Hasenfuss, G., et al. (2004). Increased neuronal nitric oxide synthase-derived NO production in the failing human heart. Lancet 363, 1365-1367.

Davis, J. P., and Tikunova, S. B. (2008). $\mathrm{Ca}(2+)$ exchange with troponin $\mathrm{C}$ and cardiac muscle dynamics. Cardiovasc. Res. 77, 619-626.

Denicola, A., Souza, J. M., and Radi, R. (1998). Diffusion of peroxynitrite across erythrocyte membranes. Proc. Natl. Acad. Sci. U.S.A. 95, 3566-3571.

Dhar, A., Kaundal, R. K., and Sharma, S. S. (2006). Neuroprotective effects of FeTMPyP: a peroxynitrite decomposition catalyst in global cerebral ischemia model in gerbils. Pharmacol. Res. 54, 311-316.

Drexler, H., Kastner, S., Strobel, A., Studer, R., Brodde, O. E., and Hasenfuss, G. (1998). Expression, activity and functional significance of inducible nitric oxide synthase in the failing human heart. J. Am. Coll. Cardiol. 32, 955-963.

Feldman, D. S., Elton, T. S., Sun, B., Martin, M. M., and Ziolo, M. T. (2008). Mechanisms of disease: detrimental adrenergic signaling in acute decompensated heart failure. Nat. Clin. Pract. Cardiovasc. Med. 5 , 208-218.

Ferdinandy, P. (2006). Peroxynitrite: just an oxidative/nitrosative stressor or a physiological regulator as well? Br. J. Pharmacol. 148, 1-3.

Ferdinandy, P., Danial, H., Ambrus, I., Rothery, R. A., and Schulz, R. (2000). Peroxynitrite is a major contributor to cytokine-induced myocardial contractile failure. Circ. Res. 87, 241-247.

Ferdinandy, P., Panas, D., and Schulz, R. (1999). Peroxynitrite contributes to spontaneous loss of cardiac efficiency in isolated working rat hearts. Am. J. Physiol. 276, H1861-H1867.
Forsmark-Andree, P., Persson, B. Radi, R., Dallner, G., and Ernster, L. (1996). Oxidative modification of nicotinamide nucleotide transhydrogenase in submitochondrial particles: effect of endogenous ubiquinol. Arch. Biochem. Biophys. 336, 113-120.

Gilad, E., Zingarelli, B., Salzman, A. L., and Szabo, C. (1997). Protection by inhibition of poly (ADP-ribose) synthetase against oxidant injury in cardiac myoblasts in vitro. J. Mol. Cell. Cardiol. 29, 2585-2597.

Hagemann, D., and Xiao, R. P. (2002). Dual site phospholamban phosphorylation and its physiological relevance in the heart. Trends Cardiovasc. Med. 12, 51-56.

Handy, D. E., and Loscalzo, J. (2006). Nitric oxide and posttranslational modification of the vascular proteome: S-nitrosation of reactive thiols. Arterioscler. Thromb. Vasc. Biol. 26, 1207-1214.

Hess, D. T., Matsumoto, A., Kim, S. O., Marshall, H. E., and Stamler, J. S. (2005). Protein S-nitrosylation: purview and parameters. Nat. Rev. Mol. Cell Biol. 6, 150-166.

Heymes, C., Bendall, J. K., Ratajczak, P., Cave, A. C., Samuel, J. L., Hasenfuss, G., et al. (2003). Increased myocardial NADPH oxidase activity in human heart failure. J. Am. Coll. Cardiol. 41, 2164-2171.

Houser, S. R., Piacentino, V. 3rd., and Weisser, J. (2000). Abnormalities of calcium cycling in the hypertrophied and failing heart. J. Mol. Cell. Cardiol. 32, 1595-1607.

Huie, R. E., and Padmaja, S. (1993). The reaction of no with superoxide. Free Radic. Res. Commun. 18, 195-199.

Ishida, H., Ichimori, K., Hirota, Y., Fukahori, M., and Nakazawa, H. (1996). Peroxynitrite-induced cardiac myocyte injury. Free Radic. Biol. Med. 20, 343-350.

Ishimura, Y., Gao, Y. T., Panda, S. P., Roman, L. J., Masters, B. S., and Weintraub, S. T. (2005). Detection of nitrous oxide in the neuronal nitric oxide synthase reaction by gas chromatography-mass spectrometry. Biochem. Biophys. Res. Commun. 338, 543-549.

Janssens, S., Pokreisz, P., Schoonjans, L., Pellens, M., Vermeersch, P., Tjwa, M., et al. (2004). Cardiomyocytespecific overexpression of nitric oxide synthase 3 improves left ventricular performance and reduces compensatory hypertrophy after myocardial infarction. Circ. Res. 94, 1256-1262.

Kamat, J. P. (2006). Peroxynitrite: a potent oxidizing and nitrating 
agent. Indian J. Exp. Biol. 44, 436-447.

Katori, T., Donzelli, S., Tocchetti, C. G., Miranda, K. M., Cormaci, G., Thomas, D. D., et al. (2006). Peroxynitrite and myocardial contractility: in vivo versus in vitro effects. Free Radic. Biol. Med. 41, 1606-1618.

Khan, S. A., Lee, K., Minhas, K. M., Gonzalez, D. R., Raju, S. V., Tejani, A. D., et al. (2004). Neuronal nitric oxide synthase negatively regulates xanthine oxidoreductase inhibition of cardiac excitation-contraction coupling. Proc. Natl. Acad. Sci. U.S.A. 101, 15944-15948.

Khan, S. A., Skaf, M. W., Harrison, R. W., Lee, K., Minhas, K. M., Kumar, A., et al. (2003). Nitric oxide regulation of myocardial contractility and calcium cycling: independent impact of neuronal and endothelial nitric oxide synthases. Circ. Res. 92, 1322-1329.

Kirsch, M., and De Groot, H. (2002). Formation of peroxynitrite from reaction of nitroxyl anion with molecular oxygen. J. Biol. Chem. 277, 13379-13388.

Knyushko, T. V., Sharov, V. S., Williams, T. D., Schoneich, C., and Bigelow, D. J. (2005). 3-Nitrotyrosine modification of SERCA2a in the aging heart: a distinct signature of the cellular redox environment. Biochemistry 44, 13071-13081.

Kohr, M. J., Aponte, A. M., Sun, J., Wang, G., Murphy, E., Gucek, M., et al. (2011a). Characterization of potential S-nitrosylation sites in the myocardium. Am. J. Physiol. Heart Circ. Physiol. 300, H1327-H1335.

Kohr, M. J., Sun, J., Aponte, A., Wang, G., Gucek, M., Murphy, E., et al. (2011b). Simultaneous measurement of protein oxidation and S-nitrosylation during preconditioning and ischemia/reperfusion injury with resin-assisted capture. Circ. Res. 108, 418-426.

Kohr, M. J., Davis, J. D., and Ziolo, M. T. (2009). Peroxynitrite increases protein phosphatase activity and promotes the interaction of phospholamban with protein phosphatase $2 \mathrm{a}$ in the myocardium. Nitric Oxide 20, 217-221.

Kohr, M. J., Traynham, C. J., Roof, S. R., Davis, J. P., and Ziolo, M. T. (2010). cAMP-independent activation of protein kinase A by the peroxynitrite generator SIN-1 elicits positive inotropic effects in cardiomyocytes. J. Mol. Cell. Cardiol. 48, 645-648.

Kohr, M. J., Wang, H., Wheeler, D. G., Velayutham, M., Zweier, J. L., and
Ziolo, M. T. (2008a). Biphasic effect of SIN-1 is reliant upon cardiomyocyte contractile state. Free Radic. Biol. Med. 45, 73-80.

Kohr, M. J., Wang, H., Wheeler, D. G., Velayutham, M., Zweier, J. L., and Ziolo, M. T. (2008b). Targeting of phospholamban by peroxynitrite decreases \{beta\}-adrenergic stimulation in cardiomyocytes. Cardiovasc. Res. 77, 353-361.

Konorev, E. A., Hogg, N., and Kalyanaraman, B. (1998). Rapid and irreversible inhibition of creatine kinase by peroxynitrite. FEBS Lett. 427, 171-174.

Leon, H., Baczko, I., Sawicki, G., Light, P. E., and Schulz, R. (2008). Inhibition of matrix metalloproteinases prevents peroxynitrite-induced contractile dysfunction in the isolated cardiac myocyte. Br. J. Pharmacol. 153, 676-683.

Levrand, S., Vannay-Bouchiche, C., Pesse, B., Pacher, P., Feihl, F., Waeber, B., et al. (2006). Peroxynitrite is a major trigger of cardiomyocyte apoptosis in vitro and in vivo. Free Radic. Biol. Med. 41, 886-895.

Li, L., Desantiago, J., Chu, G., Kranias, E. G., and Bers, D. M. (2000). Phosphorylation of phospholamban and troponin $\mathrm{I}$ in beta-adrenergic-induced acceleration of cardiac relaxation. Am. J. Physiol. Heart Circ. Physiol. 278, H769-H779.

Lin, H. L., Myshkin, E., Waskell, L., and Hollenberg, P. F. (2007). Peroxynitrite inactivation of human cytochrome $\mathrm{P} 450 \mathrm{~s} 2 \mathrm{~B} 6$ and $2 \mathrm{E} 1$ : heme modification and site-specific nitrotyrosine formation. Chem. Res. Toxicol. 20, 1612-1622.

Lokuta, A. J., Maertz, N. A., Meethal, S. V., Potter, K. T., Kamp, T. J., Valdivia, H. H., et al. (2005). Increased nitration of sarcoplasmic reticulum $\mathrm{Ca} 2+-$ ATPase in human heart failure. Circulation 111, 988-995.

Lopez, B. L., Liu, G. L., Christopher, T. A., and Ma, X. L. (1997). Peroxynitrite, the product of nitric oxide and superoxide, causes myocardial injury in the isolated perfused rat heart. Coron. Artery Dis. 8, 149-153.

Luoma, J. S., Stralin, P., Marklund, S. L., Hiltunen, T. P., Sarkioja, T., and Yla-Herttuala, S. (1998). Expression of extracellular SOD and iNOS in macrophages and smooth muscle cells in human and rabbit atherosclerotic lesions: colocalization with epitopes characteristic of oxidized LDL and peroxynitrite-modified proteins. Arterioscler. Thromb. Vasc. Biol. 18, 157-167.

Ma, X. L., Lopez, B. L., Liu, G. L., Christopher, T. A., and Ischiropoulos, H. (1997). Peroxynitrite aggravates myocardial reperfusion injury in the isolated perfused rat heart. Cardiovasc. Res. 36, 195-204.

Maack, C., and O'Rourke, B. (2007). Excitation-contraction coupling and mitochondrial energetics. Basic Res. Cardiol. 102, 369-392.

Macdougall, L. K., Jones, L. R., and Cohen, P. (1991). Identification of the major protein phosphatases in mammalian cardiac muscle which dephosphorylate phospholamban. Eur. J. Biochem. 196, 725-734.

Macmicking, J., Xie, Q. W., and Nathan, C. (1997). Nitric oxide and macrophage function. Annu. Rev. Immunol. 15, 323-350.

Martinez-Ruiz, A., and Lamas, S. (2004). S-nitrosylation: a potential new paradigm in signal transduction. Cardiovasc. Res. 62 , 43-52.

Mattiazzi, A., Mundina-Weilenmann, C., Vittone, L., Said, M., and Kranias, E. G. (2006). The importance of the Thr17 residue of phospholamban as a phosphorylation site under physiological and pathological conditions. Braz. J. Med. Biol. Res. 39, 563-572.

Mihm, M. J., Coyle, C. M., Schanbacher, B. L., Weinstein, D. M., and Bauer, J. A. (2001). Peroxynitrite induced nitration and inactivation of myofibrillar creatine kinase in experimental heart failure. Cardiovasc. Res. 49, 798-807.

Minhas, K. M., Saraiva, R. M., Schuleri, K. H., Lehrke, S., Zheng, M., Saliaris, A. P., et al. (2006). Xanthine oxidoreductase inhibition causes reverse remodeling in rats with dilated cardiomyopathy. Circ. Res. 98, 271-279.

Mungrue, I. N., Gros, R., You, X., Pirani, A., Azad, A., Csont, T., et al. (2002). Cardiomyocyte overexpression of iNOS in mice results in peroxynitrite generation, heart block, and sudden death. J. Clin. Invest. 109, 735-743.

Nathan, C., and Shiloh, M. U. (2000). Reactive oxygen and nitrogen intermediates in the relationship between mammalian hosts and microbial pathogens. Proc. Natl. Acad. Sci. U.S.A. 97, 8841-8848.

Pacher, P., Beckman, J. S., and Liaudet, L. (2007). Nitric oxide and peroxynitrite in health and disease. Physiol. Rev. 87, 315-424.
Pacher, P., Liaudet, L., Mabley, J., Komjati, K., and Szabo, C. (2002). Pharmacologic inhibition of poly(adenosine diphosphateribose) polymerase may represent a novel therapeutic approach in chronic heart failure. J. Am. Coll. Cardiol. 40, 1006-1016.

Palacios-Callender, M., Quintero, M., Hollis, V. S., Springett, R. J., and Moncada, S. (2004). Endogenous NO regulates superoxide production at low oxygen concentrations by modifying the redox state of cytochrome c oxidase. Proc. Natl. Acad. Sci. U.S.A. 101, 7630-7635.

Paolocci, N., Ekelund, U. E., Isoda, T., Ozaki, M., Vandegaer, K., Georgakopoulos, D., et al. (2000). cGMP-independent inotropic effects of nitric oxide and peroxynitrite donors: potential role for nitrosylation. Am. J. Physiol. Heart Circ. Physiol. 279, H1982-H1988.

Pietraforte, D., Salzano, A. M., Scorza, G., Marino, G., and Minetti, M. (2001). Mechanism of peroxynitrite interaction with ferric hemoglobin and identification of nitrated tyrosine residues. $\mathrm{CO}(2)$ inhibits heme-catalyzed scavenging and isomerization. Biochemistry 40, 15300-15309.

Pou, S., Pou, W. S., Bredt, D. S., Snyder, S. H., and Rosen, G. M. (1992). Generation of superoxide by purified brain nitric oxide synthase. J. Biol. Chem. 267, 24173-24176.

Quijano, C., Hernandez-Saavedra, D., Castro, L., McCord, J. M., Freeman, B. A., and Radi, R. (2001). Reaction of peroxynitrite with Mn-superoxide dismutase. Role of the metal center in decomposition kinetics and nitration. J. Biol. Chem. 276, 11631-11638.

Radi, R., Beckman, J. S., Bush, K. M., and Freeman, B. A. (1991a). Peroxynitrite-induced membrane lipid peroxidation: the cytotoxic potential of superoxide and nitric oxide. Arch. Biochem. Biophys. 288, 481-487.

Radi, R., Beckman, J. S., Bush, K. M., and Freeman, B. A. (1991b). Peroxynitrite oxidation of sulfhydryls. The cytotoxic potential of superoxide and nitric oxide. J. Biol. Chem. 266, 4244-4250.

Radi, R., Cassina, A., and Hodara, R. (2002a). Nitric oxide and peroxynitrite interactions with mitochondria. Biol. Chem. 383, 401-409.

Radi, R., Cassina, A., Hodara, R., Quijano, C., and Castro, L. (2002b). Peroxynitrite reactions and formation in mitochondria. Free Radic. Biol. Med. 33, 1451-1464. 
Radi, R., Rodriguez, M., Castro, L., and Telleri, R. (1994). Inhibition of mitochondrial electron transport by peroxynitrite. Arch. Biochem. Biophys. 308, 89-95.

Riobo, N. A., Clementi, E., Melani, M., Boveris, A., Cadenas, E., Moncada, S., et al. (2001). Nitric oxide inhibits mitochondrial NADH:ubiquinone reductase activity through peroxynitrite formation. Biochem. J. 359, 139-145.

Roof, S. R., Biesiadecki, B. J., Davis, J. P., Janssen, P. M., and Ziolo, M. T. (2012). Effects of increased systolic $\mathrm{Ca}(2+)$ and beta-adrenergic stimulation on $\mathrm{Ca}(2+)$ transient decline in NOS1 knockout cardiac myocytes. Nitric Oxide 27, 242-247.

Roof, S. R., Shannon, T. R., Janssen, P. M., and Ziolo, M. T. (2011). Effects of increased systolic $\mathrm{Ca}^{2+}$ and phospholamban phosphorylation during beta-adrenergic stimulation on $\mathrm{Ca}^{2+}$ transient kinetics in cardiac myocytes. Am. J. Physiol. Heart Circ. Physiol. 301, H1570-H1578.

Rork, T. H., Hadzimichalis, N. M., Kappil, M. A., and Merrill, G. F. (2006). Acetaminophen attenuates peroxynitrite-activated matrix metalloproteinase-2-mediated troponin I cleavage in the isolated guinea pig myocardium. J. Mol. Cell. Cardiol. 40, 553-561.

Sande, J. B., Sjaastad, I., Hoen, I. B., Bokenes, J., Tonnessen, T., Holt, E., et al. (2002). Reduced level of serine(16) phosphorylated phospholamban in the failing rat myocardium: a major contributor to reduced SERCA2 activity. Cardiovasc. Res. 53, 382-391.

Schildknecht, S., Van Der Loo, B., Weber, K., Tiefenthaler, K., Daiber, A., and Bachschmid, M. M. (2008). Endogenous peroxynitrite modulates PGHS-1-dependent thromboxane A2 formation and aggregation in human platelets. Free Radic. Biol. Med. 45, 512-520.

Schmidt, H. H., Hofmann, H., Schindler, U., Shutenko, Z. S., Cunningham, D. D., and Feelisch, M. (1996). No.NO from NO synthase. Proc. Natl. Acad. Sci. U.S.A. 93, 14492-14497.

Schulz, R., Dodge, K. L., Lopaschuk, G. D., and Clanachan, A. S. (1997). Peroxynitrite impairs cardiac contractile function by decreasing cardiac efficiency. Am. J. Physiol. 272, H1212-H1219.

Schulz, R., Nava, E., and Moncada, S. (1992). Induction and potential biological relevance of a $\mathrm{Ca}(2+)$ independent nitric oxide synthase in the myocardium. Br. J. Pharmacol. 105, 575-580.
Schwinger, R. H., Munch, G., Bolck, B., Karczewski, P., Krause, E. G., and Erdmann, E. (1999). Reduced $\mathrm{Ca}(2+)$-sensitivity of SERCA $2 \mathrm{a}$ in failing human myocardium due to reduced serin-16 phospholamban phosphorylation. J. Mol. Cell. Cardiol. 31, 479-491.

Shan, J., Kushnir, A., Betzenhauser, M. J., Reiken, S., Li, J., Lehnart, S. E., et al. (2010). Phosphorylation of the ryanodine receptor mediates the cardiac fight or flight response in mice. J. Clin. Invest. 120, 4388-4398.

Sommer, D., Coleman, S., Swanson, S. A., and Stemmer, P. M. (2002). Differential susceptibilities of serine/threonine phosphatases to oxidative and nitrosative stress. Arch. Biochem. Biophys. 404, 271-278.

Stojanovic, M. O., Ziolo, M. T., Wahler, G. M., and Wolska, B. M. (2001). Anti-adrenergic effects of nitric oxide donor SIN-1 in rat cardiac myocytes. Am. J. Physiol. Cell Physiol. 281, C342-C349.

Suarez-Pinzon, W. L., Mabley, J. G., Strynadka, K., Power, R. F., Szabo, C., and Rabinovitch, A. (2001). An inhibitor of inducible nitric oxide synthase and scavenger of peroxynitrite prevents diabetes development in NOD mice. J. Autoimmun. 16, 449-455.

Suarez-Pinzon, W. L., Szabo, C., and Rabinovitch, A. (1997). Development of autoimmune diabetes in NOD mice is associated with the formation of peroxynitrite in pancreatic islet beta-cells. Diabetes 46, 907-911.

Sun, J., Druhan, L. J., and Zweier, J. L. (2008). Dose dependent effects of reactive oxygen and nitrogen species on the function of neuronal nitric oxide synthase. Arch. Biochem. Biophys. 471, 126-133.

Sung, M. M., Schulz, C. G., Wang, W., Sawicki, G., Bautista-Lopez, N. L., and Schulz, R. (2007). Matrix metalloproteinase-2 degrades the cytoskeletal protein alpha-actinin in peroxynitrite mediated myocardial injury. J. Mol. Cell. Cardiol. 43, 429-436.

Szabo, C., Ferrer-Sueta, G., Zingarelli, B., Southan, G. J., Salzman, A. L., and Radi, R. (1997). Mercaptoethylguanidine and guanidine inhibitors of nitric-oxide synthase react with peroxynitrite and protect against peroxynitriteinduced oxidative damage. J. Biol. Chem. 272, 9030-9036.

Szabo, C., Zingarelli, B., O’Connor, M., and Salzman, A. L. (1996). DNA strand breakage, activation of poly
(ADP-ribose) synthetase, and cellular energy depletion are involved in the cytotoxicity of macrophages and smooth muscle cells exposed to peroxynitrite. Proc. Natl. Acad. Sci. U.S.A. 93, 1753-1758.

Terentyev, D., Viatchenko-Karpinski, S., Gyorke, I., Terentyeva, R., and Gyorke, S. (2003). Protein phosphatases decrease sarcoplasmic reticulum calcium content by stimulating calcium release in cardiac myocytes. J. Physiol. 552, 109-118.

Thiyagarajan, M., Kaul, C. L. and Sharma, S. S. (2004). Neuroprotective efficacy and therapeutic time window of peroxynitrite decomposition catalysts in focal cerebral ischemia in rats. $\mathrm{Br}$. J. Pharmacol. 142, 899-911.

Trafford, A. W., Lipp, P., O’Neill, S. C. Niggli, E., and Eisner, D. A. (1995). Propagating calcium waves initiated by local caffeine application in rat ventricular myocytes. J. Physiol. 489, 319-326.

Tuo, J., Wolff, S. P., Loft, S., and Poulsen, H. E. (1998). Formation of nitrated and hydroxylated aromatic compounds from benzene and peroxynitrite, a possible mechanism of benzene genotoxicity. Free Radic. Res. 28, 369-375.

Tziomalos, K., and Hare, J. M. (2009). Role of xanthine oxidoreductase in cardiac nitroso-redox imbalance. Front. Biosci. 14, 237-262.

Uppu, R. M., and Pryor, W. A. (1996). Carbon dioxide catalysis of the reaction of peroxynitrite with ethyl acetoacetate: an example of aliphatic nitration by peroxynitrite. Biochem. Biophys. Res. Commun. 229, 764-769.

Valko, M., Leibfritz, D., Moncol, J., Cronin, M. T., Mazur, M., and Telser, J. (2007). Free radicals and antioxidants in normal physiological functions and human disease. Int. J. Biochem. Cell Biol. 39, 44-84.

Vandsburger, M. H., French, B. A., Helm, P. A., Roy, R. J., Kramer, C. M., Young, A. A., et al. (2007). Multi-parameter in vivo cardiac magnetic resonance imaging demonstrates normal perfusion reserve despite severely attenuated beta-adrenergic functional response in neuronal nitric oxide synthase knockout mice. Eur. Heart J. 28, 2792-2798.

Vieira, H. L., Belzacq, A. S., Haouzi, D., Bernassola, F., Cohen, I., Jacotot, E., et al. (2001). The adenine nucleotide translocator: a target of nitric oxide, peroxynitrite, and 4-hydroxynonenal. Oncogene 20, 4305-4316.
Vig, M., Srivastava, S., Kandpal, U., Sade, H., Lewis, V., Sarin, A., et al. (2004). Inducible nitric oxide synthase in $\mathrm{T}$ cells regulates $\mathrm{T}$ cell death and immune memory. J. Clin. Invest. 113, 1734-1742.

Vila-Petroff, M. G., Younes, A., Egan, J., Lakatta, E. G., and Sollott, S. J. (1999). Activation of distinct cAMP-dependent and cGMPdependent pathways by nitric oxide in cardiac myocytes. Circ. Res. 84, 1020-1031.

Wang, H., Bonilla, I. M., Huang, X., He, Q., Kohr, M. J., Carnes, C. A., et al. (2012). Prolonged action potential and after depolarizations are not due to changes in potassium currents in NOS3 knockout ventricular myocytes. J. Signal Transduct. 2012, 645721.

Wang, H., Kohr, M. J., Traynham, C. J., Wheeler, D. G., Janssen, P. M., and Ziolo, M. T. (2008a). Neuronal nitric oxide synthase signaling within cardiac myocytes targets phospholamban. Am. J. Physiol. Cell Physiol. 294, C1566-C1575

Wang, H., Kohr, M. J., Wheeler, D. G., and Ziolo, M. T. (2008b). Endothelial nitric oxide synthase decreases beta-adrenergic responsiveness via inhibition of the L-type $\mathrm{Ca} 2+$ current. Am. J. Physiol. Heart Circ. Physiol. 294, H1473-H1480.

Wang, H., Kohr, M. J., Traynham, C. J., and Ziolo, M. T. (2009). Phosphodiesterase 5 restricts NOS3/Soluble guanylate cyclase signaling to L-type $\mathrm{Ca} 2+$ current in cardiac myocytes. J. Mol. Cell. Cardiol. 47, 304-314.

Wang, H., Viatchenko-Karpinski, S., Sun, J., Gyorke, I., Benkusky, N. A., Kohr, M. J., et al. (2010). Regulation of myocyte contraction via neuronal nitric oxide synthase: role of ryanodine receptor S-nitrosylation. J. Physiol. 588, 2905-2917.

Wang, P., and Zweier, J. L. (1996). Measurement of nitric oxide and peroxynitrite generation in the postischemic heart. Evidence for peroxynitrite-mediated reperfusion injury. J. Biol. Chem. 271, 29223-29230.

Wang, W., Sawicki, G., and Schulz, R. (2002). Peroxynitriteinduced myocardial injury is mediated through matrix metalloproteinase-2. Cardiovasc. Res. 53, 165-174.

Wu, F., and Wilson, J. X. (2009). Peroxynitrite-dependent activation of protein phosphatase type 2A mediates microvascular endothelial barrier dysfunction. Cardiovasc. Res. 81, 38-45. 
Xia, Y., Dawson, V. L., Dawson, T. M., Snyder, S. H., and Zweier, J. L. (1996). Nitric oxide synthase generates superoxide and nitric oxide in arginine-depleted cells leading to peroxynitrite-mediated cellular injury. Proc. Natl. Acad. Sci. U.S.A. 93, 6770-6774.

Xia, Y., Roman, L. J., Masters, B. S., and Zweier, J. L. (1998). Inducible nitricoxide synthase generates superoxide from the reductase domain. J. Biol. Chem. 273, 22635-22639.

Xia, Y., and Zweier, J. L. (1997). Superoxide and peroxynitrite generation from inducible nitric oxide synthase in macrophages. Proc. Natl. Acad. Sci. U.S.A. 94, 6954-6958.

Yin, X., Shan, Q., Deng, C., and Bourreau, J. P. (2002). Effect of SIN-1 in rat ventricular myocytes: interference with beta-adrenergic stimulation. Life Sci. 71, 287-297.

Zhang, P., Xu, X., Hu, X., Van Deel, E. D., Zhu, G., and Chen, Y. (2007). Inducible nitric oxide synthase deficiency protects the heart from systolic overload-induced ventricular hypertrophy and congestive heart failure. Circ. Res. 100, 1089-1098.

Zhang, Y. H., Zhang, M. H., Sears, C. E., Emanuel, K., Redwood, C.,
El-Armouche, A., et al. (2008). Reduced phospholamban phosphorylation is associated with impaired relaxation in left ventricular myocytes from neuronal NO synthase-deficient mice. Circ. Res. 102, 242-249.

Ziolo, M. T. (2008). The fork in the nitric oxide road: cyclic GMP or nitrosylation? Nitric Oxide 18, 153-156.

Ziolo, M. T., and Bers, D. M. (2003). The real estate of NOS signaling: location, location, location. Circ. Res. 92, 1279-1281.

Ziolo, M. T., Dollinger, S. J., and Wahler, G. M. (1998). Myocytes isolated from rejecting transplanted rat hearts exhibit reduced basal shortening which is reversible by aminoguanidine. J. Mol. Cell. Cardiol. 30, 1009-1017.

Ziolo, M. T., Harshbarger, C. H., Roycroft, K. E., Smith, J. M., Romano, F. D., Sondgeroth, K. L., et al. (2001a). Myocytes isolated from rejecting transplanted rat hearts exhibit a nitric oxidemediated reduction in the calcium current. J. Mol. Cell. Cardiol. 33, 1691-1699.

Ziolo, M. T., Katoh, H., and Bers, D. M. (2001b). Expression of inducible nitric oxide synthase depresses beta-adrenergic-stimulated calcium release from the sarcoplasmic reticulum in intact ventricular myocytes. Circulation 104, 2961-2966.

Ziolo, M. T., Katoh, H., and Bers, D. M. (2001c). Positive and negative effects of nitric oxide on $\mathrm{Ca}(2+)$ sparks: influence of betaadrenergic stimulation. Am. J. Physiol. Heart Circ. Physiol. 281, H2295-H2303.

Ziolo, M. T., Kohr, M. J., and Wang, H. (2008). Nitric oxide signaling and the regulation of myocardial function. J. Mol. Cell. Cardiol. 45, 625-632.

Ziolo, M. T., Maier, L. S., Piacentino, V. 3rd., Bossuyt, J., Houser, S. R., and Bers, D. M. (2004). Myocyte nitric oxide synthase 2 contributes to blunted beta-adrenergic response in failing human hearts by decreasing $\mathrm{Ca} 2+$ transients. Circulation 109 , 1886-1891.

Zou, M. H., Cohen, R., and Ullrich, V. (2004). Peroxynitrite and vascular endothelial dysfunction in diabetes mellitus. Endothelium 11, 89-97.

Zouki, C., Zhang, S. L., Chan, J. S., and Filep, J. G. (2001). Peroxynitrite induces integrin-dependent adhesion of human neutrophils to endothelial cells via activation of the Raf-1/MEK/Erk pathway. FASEB J. 15, 25-27.

Conflict of Interest Statement: The authors declare that the research was conducted in the absence of any commercial or financial relationships that could be construed as a potential conflict of interest.

Received: 08 October 2012; paper pending published: 31 October 2012; accepted: 26 November 2012; published online: 12 December 2012.

Citation: Kohr MJ, Roof SR, Zweier JL and Ziolo MT (2012) Modulation of myocardial contraction by peroxynitrite. Front. Physio. 3:468. doi: 10.3389/fphys. 2012.00468

This article was submitted to Frontiers in Striated Muscle Physiology, a specialty of Frontiers in Physiology.

Copyright (c) 2012 Kohr, Roof, Zweier and Ziolo. This is an open-access article distributed under the terms of the Creative Commons Attribution License, which permits use, distribution and reproduction in other forums, provided the original authors and source are credited and subject to any copyright notices concerning any third-party graphics etc. 